\title{
Refractive Results and Endothelial Cell Density After Eyecryl Phakic Intraocular Lens Implantation
}

\author{
Ufuk Urdem, ${ }^{1}$ (D) Alper Agca ${ }^{2}$ \\ 1Department of Ophthalmology, Sarkisla State Hospital, Sivas, Turkey \\ ${ }^{2}$ Department of Ophthalmology, Prof. Dr. N. Resat Belger Beyoglu Eye Training and Research Hospital, Istanbul, Turkey
}

\begin{abstract}
Objectives: This study was an examination of the refractive results and complications encountered with implantation of the Eyecryl phakic intraocular lens (IOL) (Biotech Vision Care, Luzern, Switzerland).

Methods: IOL recipients with a follow-up period of at least 2 years were included the study. Uncorrected and corrected distance visual acuity (UDVA and CDVA, respectively), central endothelial cell density (ECD), and procedure-related complication data were recorded.

Results: The study included 52 eyes from 26 patients. The efficacy index (postoperative UDVA/preoperative CDVA) was $1.32 \pm 1.09$ in the first year and I.39 \pm 1.03 in the second year. The safety index (postoperative CDVA/preoperative CDVA) was $1.69 \pm 1.16$ at the last follow-up. None of the patients lost 2 or more lines of CDVA. The mean ECD loss was $-4.5 \mathrm{I} \pm 9.69 \%$ at I year $(\mathrm{p}=0.005)$. There was no statistically significant ECD loss between the $\mathrm{I}$ - and 2-year follow-up visits $(p=0.794)$.

Conclusion: The results of Eyecryl phakic IOL implantation were favorable in terms of efficacy and safety.

Keywords: Cataract, endothelial cells, phakic intraocular lenses, postoperative complications, visual acuity.
\end{abstract}

\section{Introduction}

Phakic intraocular lens (IOL) implantation is one of the methods used for surgical correction of refractive errors. It is generally used in cases in which refractive errors cannot be corrected with corneal surgery. There are phakic IOLs that can be implanted into the anterior and posterior chambers. Posterior chamber phakic lenses have a plate-haptic design and are implanted in the sulcus.

Despite satisfactory refractive results, many angle-supported phakic IOLs have been removed from the market due to late complications $(I-3)$. On the other hand, several studies have reported positive results with regard to the efficacy and safety of iris-claw and posterior chamber phakic IOLs (4-9). The US Food and Drug Administration determined that the efficacy and safety of iris-claw phakic and posterior chamber phakic IOLs were within the acceptable limits $(4,10)$.

The efficacy of a phakic IOL is not in question; however, safety remains a matter of debate. Long-term follow-up studies are needed in order to evaluate the incidence of cataract and loss of endothelial cells related to these lenses.

The Eyecryl phakic IOL (Biotech Vision Care, Luzern, Switzerland) is a foldable, hydrophilic acrylic, plate-haptic, posterior chamber phakic IOL. The aim of this study was to evaluate the refractive results and complications of Eyecryl phakic IOL implantation 2 years after surgery.

\section{Methods}

This study was designed and performed in accordance with the Declaration of Helsinki and ethics committee approval was obtained from the Ethics Committee for Clinical Re- 
search of Taksim Training and Research Hospital on April 4, 2018. The files of patients who underwent Eyecryl phakic IOL implantation in this hospital were retrospectively reviewed, and the patients with sufficient details of a 2-year follow-up period were included in the study.

An automatic phoropter and a liquid crystal display monitor with light-emitting diode backlight were used for corrected and uncorrected distance visual acuity (CDVA and UDVA, respectively) measurements at each visit. Preoperatively, topography and pachymetry mapping was performed, and the anterior chamber depth was measured using a Sirius topographer (Costruzione Strumenti Oftalmici, Firenze, Italy). At every visit, endothelial cell counts were measured with a specular microscope (CEM-530; Nidek Co. Ltd., Aichi, Japan). The anterior chamber was evaluated with a Visante anterior segment optical coherence tomography device (Carl Zeiss Meditec AG, Jena, Germany), and the intraocular pressure was measured using a Goldmann applanation tonometer. Details of patient demographic information, refractive error, CDVA, UDVA, endothelial density, intraocular pressure, and complications were evaluated at pre- and postoperative, 6-month, and I- and 2-year examinations.

\section{Phakic Intraocular Lens and Surgical Method}

The Eyecryl phakic IOL is a foldable, hydrophilic acrylic, plate-haptic, posterior chamber phakic IOL designed to be implanted in the sulcus in phakic patients. With its own injector and cartridge system, it can be implanted with a 2.75$\mathrm{mm}$ incision and has aspherical optics with a diameter of 4.65 to $5.50 \mathrm{~mm}$ in the range of -3.00 to -23.00 diopters (D). The optics have a $320 \mu \mathrm{m}$ hole to prevent pupil block. The power of the lens to be implanted is calculated based on the patient's subjective manifest refraction and the refractive vergence formula on the company's website.

All of the patients in the study were operated on by the same surgeon following sub-tenon anesthesia. Mydriasis was achieved with preoperative topical cyclopentolate and phenylephrine drops. In all cases, a temporal corneal incision of $2.75 \mathrm{~mm}$ was created with a slit blade, and a side port was created with a microvitreoretinal blade. The anterior chamber was filled with sodium hyaluronate I\% (Provisc; Alcon Inc., Ft. Worth, TX, USA). Using the injector cartridge system, the phakic IOL was implanted in the anterior chamber while taking care not to touch the crystalline lens or the endothelium. Using a push-pull maneuver, each haptic was individually placed behind the iris. The ocular viscoelastic device in the anterior chamber was washed-out using a buffered salt solution. An irrigation/aspiration handpiece was not used in any of the surgeries. Drainage of the viscoelastic in the anterior chamber was followed by hydration of the incisions, and the operation was concluded.

\section{Statistical Analysis}

SAS version 9.4 software (SAS Institute, Cary, NC, USA) was used to perform the statistical analysis. Normal distribution was evaluated using the Shapiro-Wilk test. Paired ttests were used to analyze parametric data, and Wilcoxon tests were used to assess nonparametric data. Endothelial cell counts in the pre- and postoperative periods as well as the first and second postoperative year were evaluated using repeated analysis of variance.

\section{Results}

The study included 52 eyes from 26 patients. Eighteen of the patients $(69 \%)$ were female. The preoperative characteristics of the patients are provided in Table I. The mean CDVA of the patients was $0.30 \pm 0.19$ logarithm of the minimum angle of resolution (logMAR) pre-operatively and $0.19 \pm 0.25 \log M A R$ and $0.12+0.16$ logMAR in the first and second years, respectively. The mean UDVA of the patients was $0.24 \pm 0.21$ logMAR and $0.27 \pm 0.21 \log M A R$ in the first and second postoperative years, respectively. The efficacy index (postoperative UDVA/ preoperative CDVA) results were $1.32 \pm 1.09$ and $1.39 \pm 1.03$ in first and second years, respectively. CDVA (paired samples ttest, 2-tailed, $p=0.172$ ). Patient preoperative UDVA and postoperative CDVA can be seen in Fig. IA. Fig. IB illustrates the change in the best CDVA at the end of 2 years compared with the preoperative period. There was no loss in visual acuity in 2 patients. The safety index (postoperative CDVA/preoperative CDVA) was I.69 I. I6 at the last follow-up. None of the eyes lost more than 2 lines of CDVA. In all, 33\% of the eyes gained 2 or more lines of CDVA.

The mean spherical equivalent (SE) of the patients at the end of the follow-up period was $0.61 \pm 0.64 \mathrm{D}$. The SE was within the range of $-1.25 \mathrm{D}$ in all patients with $\pm 1.00 \mathrm{D}$ in $\pm 88 \%$ and $\pm 0.50 \%$ in $52 \%$. The distribution of the study patients' refractive error is shown in Figure I C-E. Figure I F shows the change in SE during the follow-up period. The SE was $-0.34 \pm 0.65 \mathrm{D}$ in the sixth postoperative month and increased to $-0.61 \pm 0.64 \mathrm{D}$ in the second year $(p<0.005$; paired samples $t$-test, 2 -tailed $p$ value).

Table I. Preoperative characteristics

\begin{tabular}{lc} 
Parameter & Mean $\pm S D$ (Range) \\
\hline Age (years) & $32.54 \pm 7.60(23.0$ to 49.0$)$ \\
SE (D) & $-13.44 \pm 3.25(-7.13$ to -20.00$)$ \\
Astigmatism (D) & $1.05 \pm 0.7 \mathrm{I}(0.00$ to 2.25$)$ \\
Axial lenght (D) & $28.08 \pm 1.17(24.15$ to $29.6 \mathrm{I})$ \\
Anterior chamber depth $(\mu \mathrm{m})$ & $3.66 \pm 0.22(3.04$ to 4.04$)$ \\
Mean keratometry (D) & $44.58 \pm \mathrm{I} .75(39.2 \mathrm{I}$ to 47.49$)$ \\
Corneal thickness (Thinnest, $\mu \mathrm{m})$ & $526 \pm 36(452$ to 595$)$ \\
\hline
\end{tabular}

SD: standard deviation; SE: spherical equivalent; D: diopters. 


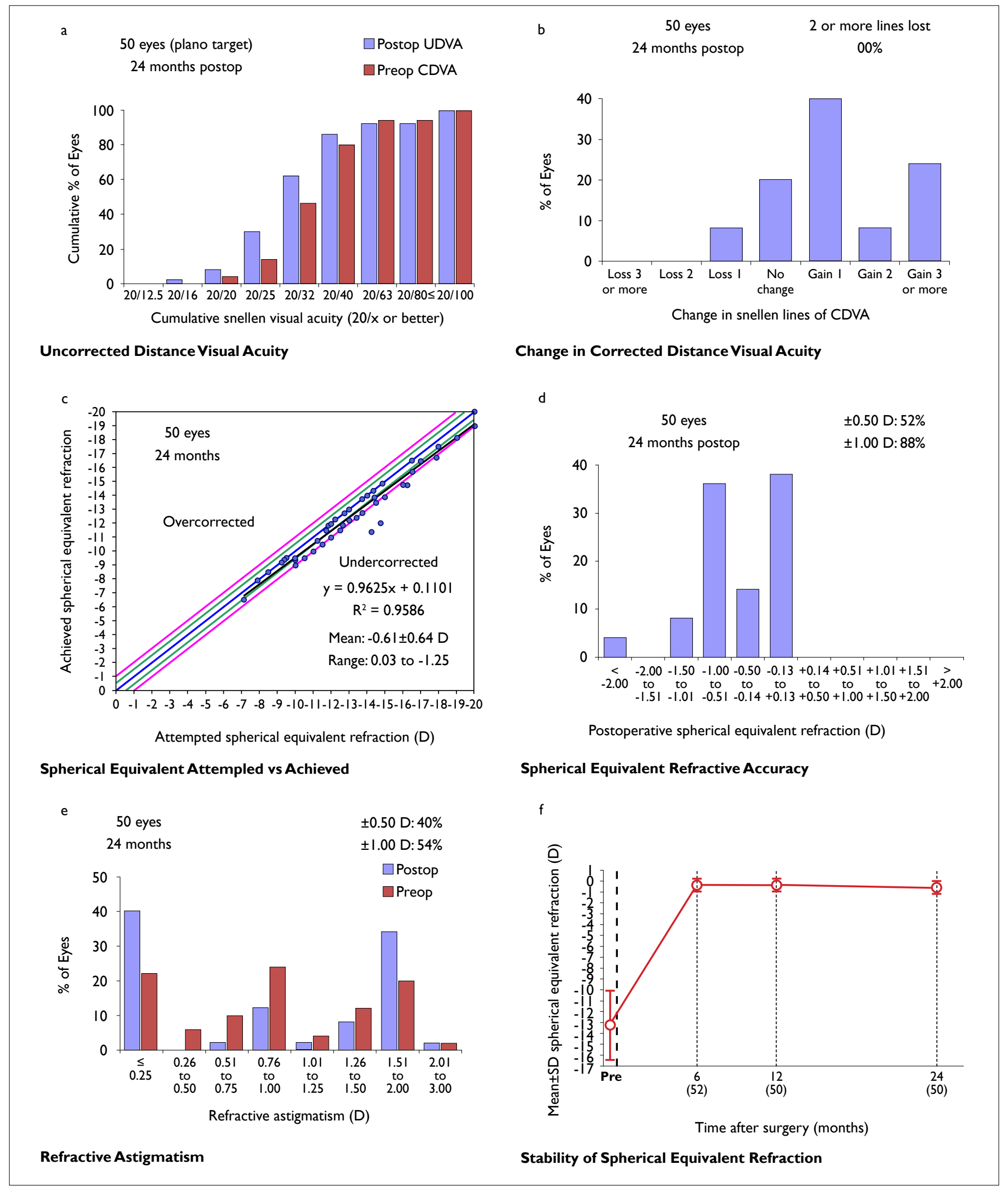

Figure I. (a) Cumulative uncorrected and corrected distance visual acuity (UDVA and CVDA, respectively); (b) Change in CVDA; (c) Spherical equivalent of attempted versus achieved refraction; (d) Accuracy of spherical equivalent refraction; (e) Pre- and postoperative refractive astigmatism; (f) Accuracy of spherical equivalent refraction. 


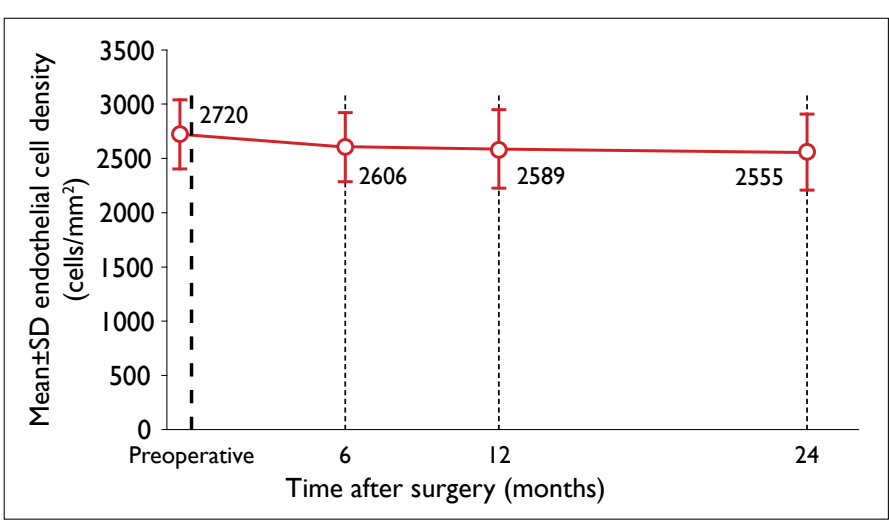

Figure 2. Endothelial cell density during follow-up.

Figure 2 shows the change in central endothelial cell density (ECD). The mean preoperative ECD was $2720 \pm 338$ cells/ $\mathrm{mm} 2$, and decreased to $2606 \pm 305$ cells $/ \mathrm{mm}^{2}$ at the 6 -month examination $(p=0.015$; paired samples t-test, 2-tailed $p$ value). The mean ECD at the I-year postoperative visit was $2589 \pm 37 \mathrm{I}$ cells $/ \mathrm{mm}^{2}$ and was not significantly different from the 6-month visit $(p=0.005$; paired samples t-test, 2-tailed $P$ value). The mean ECD at the 2-year postoperative visit was $2555 \pm 358$ cells $/ \mathrm{mm}^{2}$ and was not significantly different from the ECD at the I-year visit $(p=0.794$; paired samples t-test, 2-tailed $p$ value). The mean ECD decrease at I year was $4.5 \mathrm{I} \pm 9.69 \%$. There was a mean decrease of $0.98 \pm 8.98 \%$ between the I- and 2-year visits. The cumulative mean reduction in ECD was $5.67 \pm 10.8 \%$ at the 2 -years postoperative evaluation.

\section{Discussion}

In this study, similar to other phakic IOL implantation series in the literature, the expected increase in UDVA after the Eyecryl phakic IOL implantation was observed $(5,8)$. The safety index in this study was $>1.0$, indicating that the mean patient CDVA had increased after the operation. Seventytwo percent of the patients had >I lines of CDVA-related improvement. Although only $52 \%$ of the patients were within $\pm 0.50 \mathrm{D}$, an efficacy index of $>1.0$ was achieved. In other words, although $48 \%$ of patients had a refractive error of $-0.50 \mathrm{D}$ to $-1.25 \mathrm{D}$, the mean UDVA was higher than the mean preoperative CDVA. A high efficacy index refractive error was probably due to CDVA improvement. The CDVA improvement after surgical correction of a high refractive error is well known (1I-14). Analysis of the targeted and achieved refractive corrections revealed a slight low correction tendency and the average SE increased steadily through the second year. The patients' mean preoperative axial length included in the study was $28.05 \mathrm{~mm}$, the mean SE was -13.20 $\mathrm{D}$, and the mean age was $32.54 \pm 7.60$ years. Accordingly, we believe that that patients in this study had progressive myopia due to an increase in axial length, and an increase in the mean SE at the 2-year follow-up was an expected result. However, because of the retrospective nature of the study, it is not possible to make a definitive judgment because of the absence of postoperative axial length measurements.

To the best of our knowledge, there are no published results in the literature concerning long-term follow-up of the phakic IOL used in our study. However, the implantable collamer lens (ICL) is very similar, and there are reports of 10 years of follow-up with the ICL $(15,16)$. Fernández-Vega-Cueto et al. (I7) found that prior to implantation of the Visian ICL (Staar Surgical AG, Nidau, Switzerland), the mean SE was $-8.30 \pm 2.98 \mathrm{D}$; after surgery, it was $-0.19 \pm 0.32 \mathrm{D}$, $-0.29 \pm 0.38 \mathrm{D}$, and $-0.37 \pm 0.47 \mathrm{D}$ at 12,24 , and 36 months, respectively. They reported that the regression between the first and third years was statistically significant. Lee et al. (5) reported that the mean SE had decreased to $-0.58 \pm 0.72 \mathrm{D}$ in patients with a follow-up period of at least 5 years and $69.8 \%$ of the patients were within $\pm 0.50 \mathrm{D}$. Guber et al. (16) reported a safety index of $1.25 \pm 0.57$ at the 10 -year followup with an average SE of $0.7 \mathrm{D}$. Moya et al. (I5) stated that the SE was $-1.77 \pm I .93 \mathrm{D}$ in the last examination of I44 patients after 12 years of follow-up. The relatively good refractive outcomes in the early period and the high efficacy index in the long run, despite myopic shifts, are common points in all of these studies and in our study. This probably results from the increase in patients' best CDVA.

Although several phakic IOL models have been withdrawn from the market, the problem was never the failure to achieve refractive success or a satisfactory UDVA, but were complications due to the phakic IOL implantation $(3,18)$.

After phakic IOL implantation, severe complications, such as endothelial decompensation, cataracts, and glaucoma may occur. To our knowledge, there is no reported case of endothelial decompensation after ICL implantation, except for a few cases that developed endothelial decompensation after trauma and dislocation. On the other hand, endothelial cell loss after ICL implantation may be above normal physiological loss even in the long term (10). Torun et al. (I8) reported complications after implantation of a posterior chamber phakic IOL (PRL; Carl Zeiss Meditec AG, Jena, Germany), which was subsequently removed from the market. The study enrolled 52 eyes and the mean length of follow-up was $86 \pm 2$ I months. The mean endothelial cell loss at the last follow-up was $6.4 \%$. In our study, the mean endothelial cell loss at I year was $4.5 \mathrm{I} \%$. However, there was no significant endothelial cell loss between the first and second years after Eyecryl posterior chamber phakic lens implantation. Although these results indicate a decrease in ECD in the first year and a stabilization thereafter, prospective studies with a longer follow-up period are needed to determine if the endothelial loss rate is greater than the physiological loss. 
Another potential complication of posterior chamber phakic IOLs is cataract formation. Guber et al. (16) reported an incidence of cataract after ICL implantation of $4.9 \%$ after 5 years and $18.3 \%$ after 10 years.

However, the incidence of cataracts may vary depending on the design of the posterior chamber lens and the characteristics of the material. For example, the incidence of cataracts after implantation of a phakic refractive lens that was removed from the market for other issues may be lower than that of an $\operatorname{ICL}(19,20)$. However, a direct comparison between posterior chamber phakic IOLs of different designs do not yet exist in the literature. In our study, 2 eyes (4\%) of a patient had anterior subcapsular cataract after Eyecryl phakic IOL implantation. Nonetheless, the incidence of cataract formation may be higher in the long term, and longer follow-up periods are required. Although glaucoma can be seen after both anterior and posterior chamber phakic IOL implantation, none of our patients had pigment dispersion or high intraocular pressure requiring medical treatment in 2 years of follow-up.

One of the weak aspects of this study is its retrospective design. Due to the retrospective nature of the research, it was not possible to analyze the relationship between the axial lengths of the patients and myopic refractive shift during the follow-up period. Another weakness of the study is that although the follow-up period and number of patients were sufficient to analyze the data concerning the refractive results and early complications, the follow-up period may not have been sufficient to analyze complications such as cataract development and endothelial cell loss, which may become evident during a longer follow-up. Also, the number of the eyes was insufficient to analyze complications that are less likely to develop, such as glaucoma and retinal detachment. However, this study reports the 2-year results of a posterior chamber phakic IOL with a relatively adequate number of patients for the first time. The fact that all of the operations were performed by a single surgeon is another strength of the study because it minimizes surgeon-related variables.

In conclusion, we have retrospectively evaluated the results of Eyecryl phakic IOL implantation in our clinic. In this study, the results were positive in terms of efficacy and safety indices. No serious complications with the potential to affect CDVA were observed; however, cataracts developed in 2 eyes (4\%). Cataract development may have serious implications in eyes with pathological myopia due to an increased risk of retinal detachment after cataract surgery in these eyes. Studies with a longer follow-up period are needed to clarify the incidence of cataract after implantation of the Eyecryl phakic IOL.

\section{Disclosures}

Ethics Committee Approval: Ethics Committee approval was obtained from the Ethics Committee for Clinical Research of Taksim Training and Research Hospital (04.04.2018, No: 35)
Peer-review: Externally peer-reviewed.

Conflict of Interest: None declared.

Authorship Contributions: Involved in design and conduct of the study (UU, AA); preparation and review of the study (UU, AA); data collection (UU, AA); and statistical analysis (UU, AA).

\section{References}

I. Güell JL, Morral M, Kook D, Kohnen T. Phakic intraocular lenses part I: historical overview, current models, selection criteria, and surgical techniques. J Cataract Refract Surg 2010;36:1976-93.

2. Kohnen T, Kook D, Morral M, Güell JL. Phakic intraocular lenses: part 2: results and complications. J Cataract Refract Surg 2010;36:2168-94. [CrossRef]

3. Kohnen T, LaFontaine L, Andrew R; Study Investigators. Longterm safety follow-up of an anterior chamber angle-supported phakic intraocular lens. J Cataract Refract Surg 2017;43:1 1631 170. [CrossRef]

4. Stulting RD, John ME, Maloney RK, Assil KK, Arrowsmith PN, Thompson VM; U.S. Verisyse Study Group. Three-year results of Artisan/Verisyse phakic intraocular lens implantation. Results of the United States Food And Drug Administration clinical trial. Ophthalmology 2008; I 15:464-72.el. [CrossRef]

5. Lee J, Kim Y, Park S, Bae J, Lee S, Park Y, et al. Long-term clinical results of posterior chamber phakic intraocular lens implantation to correct myopia. Clin Exp Ophthalmol 2016;44:48I-7.

6. Kobashi H, Kamiya K, Igarashi A, Matsumura K, Komatsu M, Shimizu K. Long-term quality of life after posterior chamber phakic intraocular lens implantation and after wavefront-guided laser in situ keratomileusis for myopia. J Cataract Refract Surg 2014;40:2019-24. [CrossRef]

7. Dick HB, Budo C, Malecaze F, Güell JL, Marinho AA, Nuijts RM, et al. Foldable Artiflex phakic intraocular lens for the correction of myopia: two-year follow-up results of a prospective European multicenter study. Ophthalmology 2009;1 16:67I-7.

8. Bohac M, Anticic M, Draca N, Kozomara B, Dekaris I, Gabric $\mathrm{N}$, et al. Comparison of Verisyse and Veriflex Phakic Intraocular Lenses for Treatment of Moderate to High Myopia 36 Months after Surgery. Semin Ophthalmol 2017;32:725-733. [CrossRef]

9. Alfonso JF, Baamonde B, Fernández-Vega L, Fernandes $P$, González-Méijome JM, Montés-Micó R. Posterior chamber collagen copolymer phakic intraocular lenses to correct myopia: five-year follow-up. J Cataract Refract Surg 201 I;37:873-80.

10. Sanders DR, Doney K, Poco M; ICL in Treatment of Myopia Study Group. United States Food and Drug Administration clinical trial of the Implantable Collamer Lens (ICL) for moderate to high myopia: three-year follow-up. Ophthalmology 2004; I I : 1683-92. [CrossRef]

II. Ağca A, Çakır İ, Tülü Aygün B, Yaşa D, Yıldırım Y, Yıldız BK, et al. Visual and Refractive Outcomes of Small-Incision Lenticule Extraction in High Myopia: 5-Year Results. J Ophthalmol 
2018;2018:5893 I26. [CrossRef]

12. Yaşa D, Ağca A, Alkın Z, Çankaya Ki, Karaküu̧ük Y, Coşar MG, et al. Two-Year Follow-Up of Artisan Iris-Supported Phakic Anterior Chamber Intraocular Lens for Correction of High Myopia. Semin Ophthalmol 2016;31:280-4.

13. Kwon SW, Moon HS, Shyn KH. Visual improvement in high myopic amblyopic adult eyes following phakic anterior chamber intraocular lens implantation. Korean J Ophthalmol 2006;20:87-92.

14. Agca A, Ozgürhan EB, Baz O, Bozkurt E, Ozkaya A, Yaşa D, et al. Laser in situ keratomileusis in adult patients with anisometropic amblyopia. Int J Ophthalmol 2013;6:362-9.

15. Moya T, Javaloy J, Montés-Micó R, Beltrán J, Muñoz G, Montalbán R. Implantable Collamer Lens for Myopia: Assessment 12 Years After Implantation. J Refract Surg 2015;31:548-56. [CrossRef]

16. Guber I, Mouvet V, Bergin C, Perritaz S, Othenin-Girard P, Majo F. Clinical Outcomes and Cataract Formation Rates in Eyes 10 Years After Posterior Phakic Lens Implantation for Myopia.
JAMA Ophthalmol 2016. [CrossRef]

17. Fernández-Vega-Cueto L, Lisa C, Esteve-Taboada JJ, MontésMicó R, Alfonso JF. Implantable collamer lens with central hole: 3-year follow-up. Clin Ophthalmol 2018;12:2015-29. [CrossRef]

18. Torun N, Bertelmann E, Klamann MK, Maier AK, Liekfeld A, Gonnermann J. Posterior chamber phakic intraocular lens to correct myopia: long-term follow-up. J Cataract Refract Surg 2013;39:1023-8. [CrossRef]

19. Portaliou DM, Kymionis GD, Panagopoulou SI, Kalyvianaki MI, Grentzelos MA, Pallikaris IG. Long-term results of phakic refractive lens implantation in eyes with high myopia. J Refract Surg 20 I I;27:787-9I. [CrossRef]

20. Pérez-Cambrodí RJ, Piñero DP, Madrid-Costa D, Blanes-Mompó FJ, Ferrer-Blasco T, Cerviño A. Medium-term visual, refractive, and intraocular stability after implantation of a posterior chamber phakic intraocular lens to correct moderate to high myopia. J Cataract Refract Surg 201 I;37:179I-8. [CrossRef] 